ENTREPRENEURSHIP AND SUSTAINABILITY ISSUES

ISSN 2345-0282 (online) http://jssidoi.org/jesi/

2021 Volume 8 Number 4 (June)

https://doi.org/10.9770/jesi.2021.8.4(3)
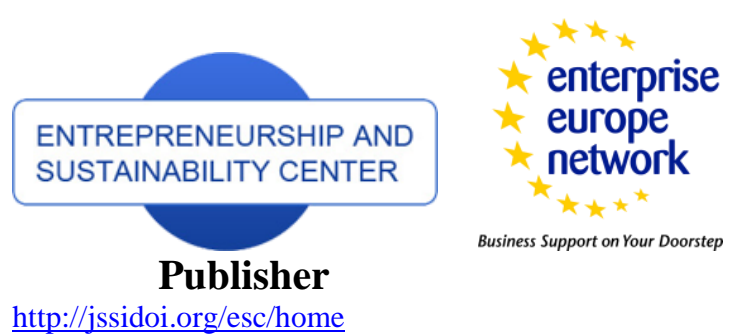

CASPA

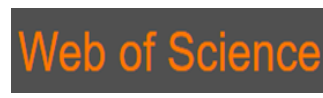

http://jssidoi.org/esc/home (

(2)

1 Clarivate

Analytics

\title{
GIVE OR BUY CONTEXTS AND INTERNET EXPERIENCE AS A FACTOR DIFFERENTIATING OF READINESS TO PROVIDE DIFFERENT TYPES OF PERSONAL DATA IN M-COMMERCE
}

\author{
Jacek Woźniak ${ }^{1}$, Alexandra Zbuchea ${ }^{2}$ \\ ${ }^{1}$ University of Economics and Human Sciences, Ul. Okopowa 59., 01-043 Warsaw, Poland \\ 2 National University of Political Studies and Public Administration, 30 A Expozitiei Blvd. Sector 1, 012104 Bucharest, \\ Romania
}

E-mails: ${ }^{1}$ j.wozniak@vizja.pl; ${ }^{2}$ alexandra.zbuchea@facultateademanagement.ro

Received 20 July 2020; accepted 20 February 2021; published 30 June 2021

\begin{abstract}
Studies show that privacy concerns are an important factor in m-commerce and m-buyers are often not ready to disclose private data to m-shops. An e-questionnaire survey was used to gather opinions in three groups - ca. 160 Poles, ca.160 Ukrainians and ca.130 Romanians, to study decisions of potential consumers concerning disclosure of personal data when downloading paid or free mobile applications in 3 different contexts: downloading an attractive app to their smartphone as a gift, as a promo purchase, or from a well-known brand. The study showed that different kinds of personal data have different fragility levels. The e-mail had the lowest level of concern, postal address a medium level, and ID and credit card numbers the highest. Context was also shown to change the kind of data respondents are willing to exchange for an attractive app. When the measure of internet experience was subjective to the length of internet use, people with higher internet experience were not found to be more unlikely to download an attractive app to their smartphone, if a condition of downloading it was providing personal identification data, in comparison with persons with low internet experience. When internet experience was measured by social norms (living in a country with a higher e-readiness index), persons with higher experience levels were less likely to download apps requiring the provision of personal data. The text ends with recommendations and suggestions for further research.
\end{abstract}

Keywords: m-commerce; m-application download; privacy; m-commerce in Eastern Europe.

Reference to this paper should be made as follows: Woźniak, J., Zbuchea, A. 2021. Give or buy contexts and internet experience as a factor differentiating of readiness to provide different types of personal data in m-commerce. Entrepreneurship and Sustainability Issues, 8(4), 53-67. https://doi.org/10.9770/jesi.2021.8.4(3)

JEL Classifications: M31, M21, O31, O33, O57

\section{Introduction}

M-commerce is understood as a form of e-shopping (a set of activities carried out in the entire purchasing cycle, namely from gathering purchase information, through closing online transactions, to post-purchase behaviors) carried out through mobile telecommunication (usually smartphones) (Koh et al. 2009; Wong et al. 2012; Groß 2016). This type of shopping is still a new phenomenon, but the dynamics of its development and the expectations that are associated with it attract a lively interest, both in practice and research. Furthermore, research on trust- 


\section{ENTREPRENEURSHIP AND SUSTAINABILITY ISSUES}

ISSN 2345-0282 (online) http://jssidoi.org/jesi/

2021 Volume 8 Number 4 (June)

https://doi.org/10.9770/jesi.2021.8.4(3)

related barriers in m-commerce (Hew 2017) is also being widely conducted, which stems, in particular, from the partial differences in the conditions of trust in this type of e-commerce (Groß 2016; Javaria et al., 2020) and the need for separate analyses for different markets, as they are characterized by different m-purchasing patterns (Cyr 2008; Zhang et al. 2012; Akman \& Rehan 2016).

Trust in e-commerce is mainly considered in the context of purchasing security (i.e. implementing procedures to secure the transfer of information) and privacy protection (i.e. not using the buyer's data for any other purpose than that agreed with the buyer). The main theoretical models that formed the basis for those studies were based on rational choice models (Ajzen 1991) either in the form of theories referring to the technology acceptance model (TAM) (Davis 1989) and its extensions (Venkatesh \& Bala 2008; Venkatesh et al. 2012; Dwivedi et al. 2019), or the diffusion innovation theory (DIT) (Rogers 1995), or finally - the theory of perceived risk (Bauer 1960; Groß 2016). Trust is an essential factor in m-commerce and it has been considered in many studies (Mondego \& Gide 2018).

However, recently, indications have emerged that this approach may not be sufficient to test m-commerce trust. An experimental study demonstrated that when providing in exchange for a \$20 coupon gift, the respondents followed their emotional assessment concerning the supplier rather than the rational decision-making model (Roghanizad \& Neufeld 2015). Likewise rating a well-known brand supplier rather than the risks associated with the purchase can explain the widespread popularity of smartphone payments for coffee in Starbucks without the feeling of threatened privacy (Hillman \& Neustaedter 2017).

These unexpected results need to be verified using samples from other countries and the analyses need to be extended to include a wider range of contextual factors that determine a smartphone user's decision because, in ecommerce, the willingness to disclose information about oneself is different for different contexts (Bandara et al., 2019; Bansal, Zahedi, \& Gefen, 2016; Gupta et al., 2010). The current study is a step in that direction. Based on an e-questionnaire conducted in three groups in different age ranges which included 167 Polish, 166 Ukrainian and 126 Romanian participants, selected factors influencing the decisions of potential consumers to make their personal data available in a situation specific to e-commerce, namely, downloading a free or paid mobile application, were analyzed. The study adds to the current body of literature also by covering a geographical area uncharted yet. Most of the investigations on trust in m-commerce are developed in China and Spain (Mondego \& Gide 2018).

The study is structured as follows. Part 2 explores the issue of downloading a mobile application in m-commerce. Part 3 contains the methodology and hypotheses of the researchers, and 4 - a discussion of the results. The current study ends with a summary presenting the main conclusions and practical recommendations. The first results of this study, based on smaller samples and without statistical analysis, were published as a conference paper (Woźniak \& Zbuchea 2018). Some phrases can be similar for both texts, especially in the section describing the methodology.

\section{Downloading a mobile application as a sample activity in m-commerce shopping}

There are three different ways of defining m-commerce in the literature, which emphasize the different business opportunities arising from the constant presence of the smartphone with the user. The first refers to making commercial transactions using mobile devices (Koh et al. 2009; Wong et al, 2012), and thus concerns mcommerce as a part of e-commerce, determined by a specific type of hardware. The second - to new business models that result from the possibility of creating services based on user location (Cliquet et al., 2014; Khare \& Rakesh, 2012). The third group of definitions, which is the most relevant for the current study, highlights the fact that the smartphone becomes a personalized communication point, which is permanently connected to the individual (Groß 2016). Emphasizing the customization of smartphones is characteristic of this group of 


\section{ENTREPRENEURSHIP AND SUSTAINABILITY ISSUES}

ISSN 2345-0282 (online) http://jssidoi.org/jesi/

2021 Volume 8 Number 4 (June)

https://doi.org/10.9770/jesi.2021.8.4(3)

definitions. It can be done by downloading mobile applications, whether they create the main access channel to the m-store or are attractive features themselves (e.g. ringtones), or enable the user to carry out additional activities that are beneficial to the (e.g. looking up a bus schedule). From the perspective of our study, it is important that a significant part of programs which provide ease of use for the smartphone owner can be downloaded free of charge from the web and users are aware that often the fee for the convenience of having this application is providing access to user personal data.

In m-business, user data - with specific purchase history and physical location - creates a business opportunity that can be evaluated and traded. The more information about the user is obtained by the m-supplier, the higher the adjustment of the services offered to their needs. At the same time, interference with their privacy is broadened. This tension - between the benefits and risks to the user resulting from the disclosure of some of the information about them - is sometimes called the personalization-privacy paradox (Lee \& Rha 2016) and it is indicated that different categories of users adopt different strategies in these situations depending, in particular, on the perception of risks in the specific situation. Perceived risks are numerous (financial, psychological, physical, time, performance, social, privacy, and security), and previous research shows that they are more prominent in $\mathrm{m}$ commerce than in e-commerce (Marriott, Williams \& Dwivedi 2017). Studies suggest that consumers are increasingly more concerned with privacy issues related to online shopping (Bardara, Fernando \& Akter 2020).

Previous studies have shown that trust is a factor that reduces the sense of risk in particular m-marketing situations (Lee \& Rha 2016). Standard ways to increase trust in e-commerce of potential users include the use of indices informing the user about the reliability of the e-shop, which can be divided into hard indices (e.g. encryption), which present the security of transactions, and soft indices (e.g. opinions of others about the quality of transactions or a well-known brand), which inform about confidentiality (Head \& Hassanein 2002; Hillman \& Neustaedter 2017). Security in m-transactions is understood as the protection of information transmitted during interaction against interception by a third party. This threat is greater in m-commerce than in e-commerce (due to lack of control of the physical environment in which the user is located) (Groß 2016). Privacy risks relate to concerns about the user's control over their data when it is collected, stored and shared with others, not only during but also after the transaction (Groß 2016). Understandably, both factors pose important barriers that may prevent e- and m-users from implementing (respectively) e- and m-transactions. Although trust is an important variable, it is not the only relevant one. Predictors of behavior in various m-marketing contexts might also be performance expectancy, effort expectancy, hedonic motivation, price value (Alalwan, Dwivedi \& Rana 2017), usefulness and ease of use (Abu-Shanab \& Ghaleb 2012).

Recently, two studies have been carried out, the results of which suggest that the conditions for a user's sense of privacy risk in m-commerce may be partially different from those in e-commerce. The first study showed that for m-buyers in the US, concerns about privacy risks are low when they make mobile transactions with well-known brands, such as paying for coffee in Starbucks via contactless payment (Hillman \& Neustaedter 2017). The study was conducted using qualitative methods, therefore it did not pose questions related to the characteristics of these consumers, and in particular to the situational and cultural specificity.

The second study concerned directly with readiness to disclose private data and was experimental. A low sense of privacy risk that results in high readiness to disclose private data is usually explained through trust in the e-shop, which restricts perceived risk of the negative consequences of one's activity, namely, one of the two factors that determine a decision based on rational assessment (the other being perceived benefits) according to the Theory of Perceived Risk (Bauer, 1960; Groß, 2016). One experimental study, where different types of data were to be provided in return for a $20 \$$ coupon gift, revealed the limits of this approach - subjects were shown to depend on their emotional evaluation of the seller, rather than to follow a rational model of decision-making (Roghanizad \& Neufeld, 2015). 


\section{ENTREPRENEURSHIP AND SUSTAINABILITY ISSUES}

ISSN 2345-0282 (online) http://jssidoi.org/jesi/

2021 Volume 8 Number 4 (June)

https://doi.org/10.9770/jesi.2021.8.4(3)

Both of these studies concern the specific context in which the m-transaction takes place, as they are not based on a general perception of trade. The first considers the contact with a well-known brand and the second concerns the exchange of gifts. Hence, the goal of our study is to check if these specific contexts can be a factor that leads to unusual behavior of m-buyers, and thus in particular whether communication with a well-known brand or the exchange of gifts are factors responsible for readiness to reveal personal data (a possible interpretation of the contexts in these situations). As Marcel Mauss (1925/1990) has stated, the situation in which gifts are exchanged creates a different set of attitudes than the context of buying and selling - it favors an attitude of reciprocating favors rather than maximizing benefits for oneself in the transaction.

It has already been observed that the willingness to disclose information about oneself in a situation of a broadly understood e-purchase is a feature that depends not only on the specificity of an entity, but also on the context in which this information is disclosed (Bansal, Zahedi, \& Gefen 2016). A social situation in which numerous people pay using smartphones can - according to the perception of social norms (Venkatesh \& Bala 2008; Venkatesh et al. 2012) - encourage unconscious perception of this activity as safe. Company brand - as respondents declare in response to direct questions - may be another way in which trust is built (Hillman \& Neustaedter 2017). In this sense, for the hypothesis presented above on the different determinants of the sense of privacy threat due to revealing personal data during purchases via smartphone, it is worth considering not only the wider contexts in which the m-transaction takes place but also those in which the social pressure resulting from the presence of others conducting transactions in a certain way is lower than in situations where nearly everyone pays for coffee using their smartphones.

Apart from the analysis of specific situational contexts, which can be different, the additional scientific knowledge brought by the current study concerns the specificity of the m-market in question. Several previous analyses have shown that the development of m-commerce in different countries follows different trajectories (Zhang, Zhung \& Liu 2012; Akman \& Rehan 2016; Chehabeddine, Tvaronavičiené, 2020). In particular, clear distinctions were identified in terms of factors conducive to the adaptation of $\mathrm{m}$-commerce (m-user readiness to enter m-transaction) between countries classified as Western and Eastern cultures, although due to the specificities of the available data, these findings were made for markets which are quite advanced in the use of $\mathrm{m}$ commerce (Zhang, Zhung \& Liu 2012) and did not cover post-socialist countries for which there is little research (Zbuchea, Vătămănescu \& Pînzaru 2015; Woźniak 2017; Woźniak \& Zbuchea 2018); in particular - studies comparing data from Poland, Romania, and Ukraine. Analyses of the factors characterizing the willingness to disclose personal data from these 3 countries complement $\mathrm{m}$-commerce research that focuses on samples from $\mathrm{m}$ markets, such as the highly developed West and South-East Asia (with Korea and Japan) (Natarajan, Balasubramanian \& Kasilingam 2017; Gupta \& Arora 2017).

Poland, Ukraine, and Romania are the three countries that - although culturally similar to each other - are reforming at different rates after the fall of the Soviet Union. All three, despite being medium developed countries, belong to undeveloped e-commerce markets. The institutional, legal and technical infrastructure for etrade is, however, slightly better in Poland than in the other two countries, evidence of which are aggregated indices such as e-readiness, which in 2015 in Poland was higher by over 10\% - this gave Poland 42nd place in world rankings. Ukraine took 64th place (upgraded from 75th place in 2012), and Romania 66th.

A slightly different view emerges from a comparison based only on access to ICT infrastructure. The ITU ICT Development Index (IDI), measured by International Telecommunication Union, combines 11 indicators on ICT access (40\% weight), use ( $40 \%$ weight) and skills ( $20 \%$ weight, measured by the number of years of education, percentage of secondary and tertiary education), capturing key aspects of ICT development for inclusive 


\section{ENTREPRENEURSHIP AND SUSTAINABILITY ISSUES}

ISSN 2345-0282 (online) http://jssidoi.org/jesi/

2021 Volume 8 Number 4 (June)

https://doi.org/10.9770/jesi.2021.8.4(3)

information societies. In 2017 ranking Poland occupied 49th place (with score 6.89), Romania - 58th (with score 6.48), and the Ukraine - 79th (5.62), among 192 economies worldwide (ITU 2017: 31).

E-markets in these countries have different sizes. The total value of e-trade turnover in 2017 was 6.671 billion Euros in Poland, and 1.17 billion Euros in Ukraine and 2.80 billion Euro for Romania (EuroCommerce, 2018). It should be remembered, however, that GDP per capita is far lower in Ukraine (c. 2,564 Euros per capita in 2019) than in Romania (c.9,928 Euro in 2019) or in Poland (c.13,165 euro), as well as the population (c. $38 \mathrm{mln}$ for Poland, $44 \mathrm{mln}$ in Ukraine and $19 \mathrm{mln}$ in Romania) and internet penetration (77\%, 67\%, 74\% respectively in 2019) (EuroCommerce 2019).

All 3 e-markets have grown rapidly from 2017 to 2018. In 2018, the e-commerce industry of Romania was worth 3.6 billion euros and the average spending per online shopper was estimated at 786 euros (based on 2015 data), according to the Ecommerce Foundation. (https://ecommercenews.eu/ecommerce-in-europe/ecommerceromania/). Online sales on Ukraine $€ 1.86$ billion (2018) with only 3.7 million of these internet users shop online and on average, online shoppers in Ukraine spend 286 euros per year (https://ecommercenews.eu/ecommerce-ineurope/ecommerce-in-ukraine/) For Romania, the Turnover growth of e-commerce was of 30\% in 2019; while for Poland was of 5\%, and the figure for Ukraine was 15\% (EuroCommerce 2019).

In 2018 in Poland, over 61 percent of the online population shop online and spend an average of 651.50 euros per year and total e-spending reached 9.31 billion euro in 2018. (https://ecommercenews.eu/ecommerce-in-poland-toreach-e11-64-billion-in-2019/). The data suggests that the experience in e- and $\mathrm{m}$ - shopping is extensive in the surveyed countries, although more experience is to be expected in relation to the problems that arise in mshopping - and therefore the awareness of privacy risks - in Poland than in other countries. Data on the scale of infrastructure availability (for which the ITU ICT Development Index may be an indicator) suggests that differences between Ukraine and Romania may also be expected.

\section{Methodology of research}

The current study aimed to check whether, in the situation presented as an exchange of gifts, smartphone users will be inclined to provide information about their private data more often than in the situation presented as a purchase at a favorable price. Also, the study's goal was to check whether there is a difference in this readiness when a purchase is made from a well-known brand than when a purchase is made in an unspecified situation, described as an online site. An additional goal of the study is to verify whether internet experience is a modifier of the strength of barriers to trust in m-commerce.

We will focus on the exchange of apps which develop the smartphone's functions as a personal center for management, communication, and entertainment, and which are free. As has been shown, this segment of the mmarket is based on creating a potential client of the user of the given application, and so income from providing the user with the app does not dominate in the sellers' business model. Users, however, are accustomed to the fact that obtaining an attractive application sometimes goes in pair with providing personal data, hence this situation is a good one for analyzing readiness to expose oneself to a threat to one's privacy in exchange for obtaining a gift with an attractive value.

It is understandable that several contextual conditions, such as the value of the sum in question, or - the negative consequences that a breach of trust may bring the buyer, modifies readiness to engage in commercial transactions. Readiness to disclose personal information should, therefore, depend on the sensitivity level of this information (Roghanizad \& Neufeld 2015), consistently with the Theory of Perceived Risk (Groß 2016). The research 


\section{ENTREPRENEURSHIP AND SUSTAINABILITY ISSUES}

ISSN 2345-0282 (online) http://jssidoi.org/jesi/

2021 Volume 8 Number 4 (June)

https://doi.org/10.9770/jesi.2021.8.4(3)

questions concern the extent to which broad contexts (defined as the exchange of gifts or a purchase) and situational contexts (defined as obtaining an application from a company with a well-known brand) as well as internet experiences, modify this readiness to provide personal data of various kinds.

Referencing the Theory of Perceived Risk (Groß 2016), it is expected that different types of information will be treated by the respondents as having different levels of sensitivity. It can be expected that data concerning e-mail or traditional mail addresses, which are generally widely available and the knowledge of which does not usually lead to material losses, will be considered insensitive.

A higher level of sensitivity can be attributed to data related to personal documents, such as the ID number. Although these types of data do not directly lead to financial losses, the request for such data may be treated by online users as unduly invasive of their privacy, not so much because of the Theory of Perceived Risk (Groß 2016), but because of the atypical nature of the request, namely, the lack of compliance with social norms prevailing in a given environment, according to factors indicated by the extended versions of the TAM model (Venkatesh \& Bala 2008; Venkatesh et al. 2012), influence the intention to use the new technology. Extended versions of TAM emphasize that, apart from perceived ease of use and perceived benefits, compliance with a social norm is the third factor determining the intention of use, so in our case - readiness to complete a certain $\mathrm{m}$ action online.

The third group of information is made up of data whose sensitivity results directly from the risk of financial losses that may result from their provision, in particular - the bank account number. Based on this argumentation and in accordance with the findings of previous studies, in particular (Roghanizad \& Neufeld 2015),

Hypothesis 1 is formulated.

H1. The readiness to provide personal data varies for different types of data

As indicated above, according to Mauss, the level of willingness to disclose data in a situation defined as a gift exchange may be higher than in a situation defined as a purchase situation, even at an attractive (discount) price. Transactions with a well-known brand company can be seen as a situation in which the buyer benefits not only from the purchase of goods but also from the prestige of the brand. Therefore, transactions in such a situation can be treated as pursuing two objectives - the exchange of gifts and purchase of a product. This way of thinking suggests that in transactions with a well-known brand company there will be a higher willingness to provide private data than in a simple purchase, which makes it partly similar to exchanging gifts.

$\mathrm{H} 2$. The frequency of providing personal data for a specific kind of information is higher if the situation is defined as an exchange of gifts, than if it is defined as an advantageous purchase with a discount.

It should be noted that Mauss's theory concerns natural (personal contact), not online interactions. This means that the condition for the impact of these different expectations is that the situation is not manipulated by the other party. Knowledge of the Internet and the dangers associated with the control Internet situations should be higher for people with more online experience. Therefore, it should be expected that people with more online experience, whether measured at the level of an individual or at the level of a country (i.e. people from a country with a higher level of Internet infrastructure) will be more aware of the scale of risks that characterize Internet interactions, and thus will be less affected by the influence of the definition of a situation as a gift.

H.3. The internet experience, measured on individual and country-level will modify the readiness to provide personal data for a specific kind of information, and higher experience leads to a lower frequency of providing personal data for a specific kind of information. 


\section{ENTREPRENEURSHIP AND SUSTAINABILITY ISSUES}

ISSN 2345-0282 (online) http://jssidoi.org/jesi/

2021 Volume 8 Number 4 (June)

https://doi.org/10.9770/jesi.2021.8.4(3)

The data for our study were collected as 3 independent samples, gathered using the snowball method by the authors' MA students in university year 2017/2018. Respondents generally have higher education (or were in college at the time) and lived in large cities (mainly Warsaw, Odessa, or Bucharest) and can be seen as representatives of 'early adopters' of new technologies and products. This slightly vague term refers to the fact that in every society some social groups tend to try out new solutions, especially of the technological kind, and it is with them that the dissemination of the technology starts (Rogers 1962). The typical socio-demographical characteristic of early adopters is similar to our respondents' as they usually are young professionals from big cities. The study base on a group of 167 Poles, 166 Ukrainians, and 126 Romanians, demographically differentiated.

As the investigation aims is to verify if internet experience, variously defined, significantly modifies readiness to provide personal data in 3 contexts: defining the situation as a gift or purchase or transaction with a well-known brand, the questionnaire constructed for the study - besides a series of questions concerning the previously made e- and m-purchases - consisted of 3 groups of questions on readiness to submit different kinds of personal data assessed on 7 points Likert scale. The 3 situations were characterized as the first an exchange of gifts, the second a purchase with a discount and the third - well-known brand context. Each question consists of 6 items:

a. I will give my e-mail address to get the attractive app [ and the context: for free, to buy on discount price]

b. I will give my full internet data - e-mail address and telephone number - [and the context: to get for free, to buy on discount price]

c. I will give my post and e-mail address [and the context: to get for free, to buy on discount price]

d. I will give my credit card number and e-mail address [and the context: to get for free, to buy on discount price]

e. I will give my credit card number and full addresses data (with my ID number) [and the context: to get for free, to buy on discount price]

f. I will withdraw from getting the attractive app if it is necessary to submit any of my personal data

(a) contains the least sensitive data (e-mail), (b) and (c) medium-sensitivity data, (d) and (e) high-sensitivity sensitivity data, and (f) a declaration to withdraw from contact if any data is needed - and is, therefore, a negative measure of readiness to provide any data, regardless of the type.

The study used several kinds of internet experience indices, but this text refers to two operationalizations:

- Respondents were classified into two groups, based on subjective declaration: as internet experienced if they responded "have used the internet for a long time", and as less internet experienced - if they responded that they "have used the internet for a long time, but really frequently not for long"; "I use the internet, but not very frequently"; or "I use the internet if I need to, but I don't feel too comfortable with it".

- $\quad$ Representing a country with higher levels of technical and social ICT infrastructure was based on the networked readiness index http://reports.weforum.org/global-information-technology-report-2016/networkedreadiness-index/. Poland takes 42ndplace in world rankings, Ukraine - 64th, Romania - 66th, so we can assume that the internet experience of people is higher in Poland and similar in the Ukraine and Romania (See Woźniak, 2015 , for an explanation of the construction of the index).

\section{Research results and discussion}

To verify Hypotheses 1 and 2, the Wilcoxon test was used to check that the differences in ranks for the same personal data between the question about the gift-exchange situation (Using a smartphone to download an app which you find attractive) differ significantly from the frequency of the purchase situation (Using a smartphone to 


\section{ENTREPRENEURSHIP AND SUSTAINABILITY ISSUES}

ISSN 2345-0282 (online) http://jssidoi.org/jesi/

2021 Volume 8 Number 4 (June)

https://doi.org/10.9770/jesi.2021.8.4(3)

download an app, which you find attractive and not expensive I will submit some of my data) for further types of data.

Table 1. Differences in the willingness to provide a specific type of information about personal data in a situation defined as an exchange of gifts and a situation defined as an 'ordinary' site

\begin{tabular}{|c|c|c|c|c|c|}
\hline \multirow{2}{*}{ Compared questions } & \multicolumn{3}{|c|}{ statistical measurements } & \multicolumn{2}{|c|}{$\begin{array}{l}\text { mean ratings concerning data- } \\
\text { sharing readiness }\end{array}$} \\
\hline & $\mathrm{Z}$ & $\mathrm{p}$ & $\mathrm{R}$ & $\begin{array}{l}\text { when the app is } \\
\text { free }\end{array}$ & $\begin{array}{l}\text { when the app is } \\
\text { purchased }\end{array}$ \\
\hline $\begin{array}{l}\text { I will give my e-mail address to get the attractive app for } \\
\text { free/ I will give my e-mail address, if it is the condition to } \\
\text { buy the app }\end{array}$ & $-3.465 b$ & 0.001 & 0.161 & 3.15 & 3.47 \\
\hline $\begin{array}{l}\text { I will give my full internet data - e-mail address and } \\
\text { telephone number - to get app for free/ [ I will give e-mail } \\
\text { address and telephone number - if it is the condition to } \\
\text { buy the app] }\end{array}$ & $-6.820 c$ & 0.000 & 0.318 & 3.96 & 3.52 \\
\hline $\begin{array}{c}\text { I will give my post and e-mail address to get app for free } \\
{[\ldots-\text { if it is the condition to buy the app }]}\end{array}$ & $-6.349 c$ & 0.000 & 0.296 & 4.24 & 3.85 \\
\hline $\begin{array}{l}\text { I will give my credit card number and e-mail address to get } \\
\text { app for free [...- if it is the condition to buy the app] }\end{array}$ & $-1.694 b$ & 0.090 & $\mathrm{Nd}$ & $\mathrm{Nd}$ & nd \\
\hline $\begin{array}{l}\text { I will give my credit card number and full addresses data } \\
\text { (with my ID number) to get app for free [...- if it is the } \\
\text { condition to buy the app] }\end{array}$ & $-1.459 \mathrm{c}$ & 0.144 & $\mathrm{Nd}$ & $\mathrm{Nd}$ & nd \\
\hline $\begin{array}{l}\text { I will withdraw from getting the attractive app, if there it is } \\
\text { necessary to submit any of my personal data }[\ldots-\text { if it is the } \\
\text { condition to buy the app] }\end{array}$ & $-3.187^{\mathrm{c}}$ & 0.001 & 0.149 & 4.03 & 3.70 \\
\hline
\end{tabular}

Source: data from research

$\mathrm{b}$ on the basis of positive ranks

$\mathrm{c}$ on the basis of negative ranks

nd - in the absence of an established relationship, the measure was not counted

The data in the table shows that low-sensitivity data is context-dependent and high-sensitivity information is not. Looking at the means, we conclude that Hypothesis 1 is confirmed only for data with the lowest sensitivity (email address) (the lesser the Likert scale value, the stronger the result, therefore in Table 1 the smaller the number the stronger the willingness to provide data for a-e, but the stronger the willingness to abandon the transaction for f).

For medium-sensitivity data, the data in table 1 confirm the opposite hypothesis, namely that in a purchase situation, respondents would be more willing to provide medium-sensitivity data, and would more often withdraw from the transaction if some data had to be provided than in a "gift exchange" situation. Such an outcome can be explained by referring to the social standards governing the defined situation - when exchanging gifts, the basis for the exchange is the free decision of the parties and not a claim of the other party to specific data, while the provision of certain insensitive data in a purchasing situation is normal practice in online shopping. This interpretation suggests that the extended version of TAM better than Mauss's face-to-face model of free exchange of gifts explains the highly routinized situation of some types of online contact.

Highly sensitive data, namely, those containing a credit card number are treated differently by the respondents and the data collected in Table 1 show that there are no significant differences in their availability, regardless of the contextual definition of the situation. This means that at the risk of a large loss (or highly unusual demands compared to market standards) the difference between the context defined as a gift and a purchase disappears in the eyes of respondents. 


\section{ENTREPRENEURSHIP AND SUSTAINABILITY ISSUES}

ISSN 2345-0282 (online) http://jssidoi.org/jesi/

2021 Volume 8 Number 4 (June)

https://doi.org/10.9770/jesi.2021.8.4(3)

Table 2. Differences in willingness to provide a specific type of information about personal data in a situation defined as an exchange of gifts and a situation defined as a purchase, broken down by respondents from Poland or Romania and Ukraine together ("ordinary" website, situation not defined)

\begin{tabular}{|c|c|c|c|c|c|}
\hline \multirow{2}{*}{ Compared questions } & \multicolumn{3}{|c|}{ statistical measurements } & \multicolumn{2}{|c|}{$\begin{array}{l}\text { mean ratings concerning data-sharing } \\
\text { readiness }\end{array}$} \\
\hline & $\mathrm{Z}$ & $\mathrm{p}$ & $\mathrm{R}$ & $\begin{array}{l}\text { when the app is } \\
\text { free (a shop) }\end{array}$ & $\begin{array}{l}\text { when the app is } \\
\text { purchased }\end{array}$ \\
\hline $\begin{array}{l}\text { I will give my e-mail address to get the attractive app for } \\
\text { free/ I will give my e-mail address, if it is the condition to } \\
\text { buy the app }\end{array}$ & $-3.465 b$ & 0,001 & 0,162 & 3,15 & 3,13 \\
\hline $\begin{array}{l}\text { I will give my full internet data - e-mail address and } \\
\text { telephone number - to get app for free/ [ I will give e-mail } \\
\text { address and telephone number - if it is the condition to } \\
\text { buy the app] }\end{array}$ & $-6.820 c$ & 0,000 & 0,319 & 3,96 & 3,53 \\
\hline $\begin{array}{c}\text { I will give my post and e-mail address to get app for free } \\
{[\ldots-\text { if it is the condition to buy the app }]}\end{array}$ & $-6.349 c$ & 0,000 & 0,297 & 4,24 & 3,84 \\
\hline $\begin{array}{l}\text { I will give my credit card number and e-mail address to get } \\
\text { app for free [...- if it is the condition to buy the app] }\end{array}$ & $-1.694 b$ & 0,090 & 0,080 & 4,78 & 4,75 \\
\hline $\begin{array}{l}\text { I will give my credit card number and full addresses data } \\
\text { (with my ID number) to get app for free }[\ldots \text { - if it is the } \\
\text { condition to buy the app] }\end{array}$ & $-1.459 c$ & 0,144 & 0,068 & 5,11 & 4,84 \\
\hline $\begin{array}{l}\text { I will withdraw from getting the attractive app, if there it is } \\
\text { necessary to submit any of my personal data }[\ldots \text { - if it is the } \\
\text { condition to buy the app] }\end{array}$ & $-3.187 \mathrm{c}$ & 0,001 & 0,150 & 4,03 & 3,62 \\
\hline
\end{tabular}

Source: data from research

$\mathrm{b}$ on the basis of positive ranks

$\mathrm{c}$ on the basis of negative ranks

nd - in the absence of an established relationship, the measure was not counted

To verify Hypothesis 3, two operationalizations of online experience were analyzed - belonging to a country with a higher level of e-readiness and subjectively declared ability of internet use. Table 2 shows that experience measured by country more (Poland) or less (Ukraine and Romania together) advanced makes a significant difference in providing low-sensitivity information between respondents from more and less experienced countries, as well as the willingness to give up transactions. As before, providing credit card data does not depend on such measured knowledge of the Internet and the risks it poses.

Online experience measured at the individual level (data not included in the text) turned out to be a statistically not significant factor differentiating the varied willingness to provide data in a situation of purchase and gift exchange (data omitted in the study), both in the entire group of respondents (i.e. 450 people), as well as in countries with a lower level of e-readiness (i.e. among respondents from Romania and Ukraine as one group). The Polish group only differentiated willingness to withdraw from the transaction when any data is required (item $\mathrm{f}$ Wilcoxon test value-based on negative ranks $z=-2.301$, significance 0,021 ). This suggests that in the group of respondents with extensive internet experience, both personal and social, the "transparency" of the situation of contact with the company on the Internet is the highest, and regardless of its formulation, whether as a gift or as a purchase, it is understood that privacy is threatened by the provision of personal data. Considering this group as an indicator for the future development of Internet users' personal data behavior, it can be said that this result suggests a growing awareness of and low level of trust in the goals of online providers. 


\section{ENTREPRENEURSHIP AND SUSTAINABILITY ISSUES}

ISSN 2345-0282 (online) http://jssidoi.org/jesi/

2021 Volume 8 Number 4 (June)

https://doi.org/10.9770/jesi.2021.8.4(3)

Table 3. Differences in the willingness to provide a specific type of personal data information in a situation defined as an exchange of gifts ("ordinary shop") and a situation defined as a purchase from a company with a well-known brand name.

\begin{tabular}{|c|c|c|c|c|c|}
\hline \multirow[b]{2}{*}{ Compared questions } & \multicolumn{3}{|c|}{ statistical measurements } & \multicolumn{2}{|c|}{$\begin{array}{c}\text { mean ratings concerning data-sharing } \\
\text { readiness }\end{array}$} \\
\hline & $\mathrm{Z}$ & $\mathrm{p}$ & $\mathrm{R}$ & $\begin{array}{l}\text { when the app is } \\
\text { purchased from a } \\
\text { well-known brand }\end{array}$ & $\begin{array}{l}\text { when the app is } \\
\text { given for free }\end{array}$ \\
\hline $\begin{array}{l}\text { I will give my e-mail address to get the attractive app for } \\
\text { free/ I will give my e-mail address, if it is the } \\
\text { condition to buy from well-known brand] }\end{array}$ & $-.299^{b}$ & 0,765 & $\mathrm{Nd}$ & 3,13 & 3,15 \\
\hline $\begin{array}{l}\text { I will give my full internet data - e-mail address and } \\
\text { telephone number - to get app for free/ [ I will give e- } \\
\text { mail address and telephone number - if it is the } \\
\text { condition to buy the app from well-known brand] }\end{array}$ & $-7.100^{c}$ & 0,000 & 0,334 & 3,53 & 3,96 \\
\hline $\begin{array}{l}\text { I will give my post and e-mail address to get app for free } \\
\text { [...- if it is the condition to buy the app from well- } \\
\text { known brand] }\end{array}$ & $-6.196^{c}$ & 0,000 & 0,291 & 3,84 & 4,24 \\
\hline $\begin{array}{l}\text { I will give my credit card number and e-mail address to } \\
\text { get app for free [...- if it is the condition to buy the } \\
\text { app from well-known brand] }\end{array}$ & $-.619^{b}$ & 0,536 & $\mathrm{Nd}$ & 4,75 & 4,78 \\
\hline $\begin{array}{l}\text { I will give my credit card number and full addresses data } \\
\text { (with my ID number) to get app for free [...- if it is the } \\
\text { condition to buy the app from well-known brand] }\end{array}$ & $-3.755^{c}$ & 0,000 & 0,176 & 4,84 & 5,11 \\
\hline $\begin{array}{l}\text { I will withdraw from getting the attractive app, if there it } \\
\text { is necessary to submit any of my personal data }[\ldots-\text { if it } \\
\text { is the condition to buy the app from well-known } \\
\text { brand] }\end{array}$ & $-3.561^{\mathrm{c}}$ & 0,000 & 0,167 & 3,62 & 4,03 \\
\hline
\end{tabular}

$\mathrm{b}$ on the basis of positive ranks

$\mathrm{c}$ on the basis of negative ranks

nd - in the absence of an established relationship, the measure was not counted

The results in Table 3 demonstrate that the situation of purchase in a well-known brand company is treated - in terms of willingness to provide personal data at the seller's request - differently from the situation of a gift exchange with an unspecified company (where the willingness to provide personal data was highest). Moreover, the differences consider not only to the willingness to provide low-sensitivity data such as e-mail and postal addresses but also to credit card information and ID number. Only data combining e-mail address and credit information data are similarly sensitive in both contexts. This result seems to confirm the data obtained in the U.S. Starbucks pay study - regardless of the social pressure that is likely to be exerted by the sight of other payers on the phone, respondents are more likely to provide high-sensitivity personal information (including credit card data) to companies with known macros than, even in their preferred situation, to companies with unknown brands.

To sum up, the data collected in the study allowed to partially confirm Hypotheses 1 and 2 for some personal data, and Hypothesis 3 for the Internet experience understood as belonging to a country with a higher level of ereadiness. However, it overturned the results for Internet experience measured according to declarations of extensive online experience.

\section{Conclusions}

The current study aimed to check whether, in a situation defined as a gift exchange, users will more likely to provide personal data information. The goal was also to verify whether a similar phenomenon in transactions with well-known brands occurs, and whether knowledge of the risks associated with making personal data available on the Internet, measured by the declared Internet experience and belonging to a country with a higher level of e-readiness (which measures the state of social, legal and technical infrastructure) modifies these relationships. 


\section{ENTREPRENEURSHIP AND SUSTAINABILITY ISSUES}

ISSN 2345-0282 (online) http://jssidoi.org/jesi/

2021 Volume 8 Number 4 (June)

https://doi.org/10.9770/jesi.2021.8.4(3)

The study demonstrated that a higher willingness to disclose personal data in a gift exchange situation concerns only the lowest sensitivity data (e-mail address), while for medium sensitivity data (postal address and phone number) the opposite hypothesis was confirmed. No differences were reported in the willingness to provide data in each of the two contexts for the most sensitive data which may bear financial risks, for example - credit card information. It was also demonstrated that extensive online experience, measured by belonging to a country with a higher level of social and legal infrastructure, differentiates these two dependencies for low and mediumsensitive data, while there are no such differences for data with the highest sensitivity. Online experience, measured by individual declarations of the respondents, was only a factor when withdrawing from transactions if any personal data was required, and did not differentiate the decisions concerning the provision of specific categories of data.

This result indicates that the interpretation of the situation of downloading smartphone applications free of charge but in exchange for certain personal data as a gift exchange situation is very limited in scope, namely, it only adequately describes the exchange of applications for the least sensitive data (e-mail address), that is, with almost no risk for the user. Users often create separate e-mail addresses for e-commerce and m-commerce purposes, treating them as (almost) non-personal data, which would explain the willingness to provide them when "gifts" are exchanged. At the same time, the fact that greater awareness of the threats posed by providing personal data on the Internet (measured by the standards of a country with more experience in this area) differentiates the willingness to provide the least sensitive data (and to withdraw from a transaction when any data needs to be given) suggests that with increasing knowledge of the Internet, even a situation of gift exchange for less sensitive data will be treated by m-users as suspicious - it will not encourage them to give information about themselves. It is, therefore, to be expected that users will be increasingly sensitive to the protection of their personal data of all kinds, as their online experience grows.

The second research question concerned the specifics of transactions with well-known brands. The results confirmed that users are willing to provide their personal data more frequently when a transaction involves a well-known brand company, compared to a situation defined as an exchange of gifts with an unspecified company. The differences concerned medium and high sensitivity information, which confirmed previous findings regarding the willingness to make Starbucks payments using a smartphone. What it means, is that this tendency appears regardless of social norm pressure arising from looking at other people paying in this way (i.e. a known brand influences trust as an additional factor).

Both of these results allow the formulation of several practical recommendations. First of all, to obtain personal data for a company, it is effective for them to use one of their well-known brands, especially when the company wants to obtain very sensitive data. Offering "gifts" in exchange for personal data in the form of free smartphone applications can be an effective way to obtain only low-sensitivity data.

A second important practical consequence of the results of our study is the limited extent to which smartphone users will be willing to give out their personal data in exchange for free gadgets such as phone apps - with more online experience, users should be expected to be more sensitive to protecting their personal data.

From a scientific knowledge perspective, the study showed that the Theory of Perceived Risk explains the decisions of users in both studies, which became the starting point for the current study. The assessment of a company, or more precisely, the recognition of their brand as "well-known" changes the perception of risks in a transaction with such a company. Our results demonstrated that users are ready to provide a wide range of personal information when they enter into transactions with well-known brands, which suggests a different risk assessment in such a situation, rather than undermines the rational decision-making model. Confirmation of this suggestion, however, requires further research, aimed at a more accurate description of the user's decision- 


\section{ENTREPRENEURSHIP AND SUSTAINABILITY ISSUES}

ISSN 2345-0282 (online) http://jssidoi.org/jesi/

2021 Volume 8 Number 4 (June)

https://doi.org/10.9770/jesi.2021.8.4(3)

making path, as our data is based on the declared results of the decision and not on the process of arriving at the said decision.

The second direction of future research, which is suggested by the results obtained here, concerns the measurement of knowledge about the risks involved in sharing personal data on the Internet. The two measures of this knowledge adopted here - the declared efficiency of using the Internet and living in a country with a certain level of socio-technical infrastructure indexed by e-readiness - are not precise, and are indirect indicators for a specific type of knowledge about threats. Basing this study on such distant indicators is one of the important limitations for the interpretation of the results obtained here. The need to search for good indicators for the levels of "general online culture" of the respondent is another direction of research suggested by the results obtained here. Direct declarations of online activity (through years of using a given tool, or a subjective declaration) although attractive in terms of measurement, because the resulting measurement tool consists of one or two questions - are becoming increasingly unreliable, as they do not differentiate well between modern users. Alternative methodologies, which measure online familiarity on a scale of activity in the use of selected online tools, are not very well suited to the assessment of personal data risks and are cumbersome to measure due to the length of the questionnaire. From a methodological point of view, it is, therefore, necessary to continue to look for a short tool that reflects well the different levels of knowledge about the risks involved in making various types of data available online.

In conclusion, the study demonstrated that the mechanisms involved in providing personal data in m-transactions are more complicated than the TAM model with its additions and the Mauss model of personal gif exchange suggest. It has also been shown that transactions with well-known brands appear to be governed by separate rules from those with an unspecified website and that the online experience contributes to decreased readiness to provide certain types of personal data in both contexts. The underlying limitations for these conclusions, apart from the incidenality of the samples on which our study is based and the assumed operationalization of the indicators, are on self-reports of the undertaken behaviors (questionnaire responses), and not actual action in a situation of "temptation" to obtain an attractive application in exchange for entering some data. It can be expected that in a study inducing certain behavior (without exploring the intention), the tendency to provide personal data will turn out to be higher than that obtained in the current study. Confirmation of this suggestion requires further research, with a differently constructed methodology.

\section{References}

Abu-Shanab; E. \& Ghaleb; O. 2012. Adoption of mobile commerce technology: An involvement of trust and risk concerns. International Journal of Technology Diffusion 3(2): 36-49.

Alalwan, A.A.; Dwivedi, Y.K.; \& Rana, N.P. 2017. Factors influencing adoption of mobile banking by Jordanian bank customers: Extending UTAUT2 with trust. International Journal of Information Management 37(3): 99-110. https://doi.org/10.1016/j.ijinfomgt.2017.01.002

Ajzen, I. 1991. The theory of planned behavior. Organizational Behavior and Human Decision Processes 50(2): $179-211$.

Akman, I.; \& Rehan, M. 2016. Examination of factors influencing employees' adoption of mobile commerce and services in Turkey. Economic Research-Ekonomska Istraživanja 29(1): 770-781. https://doi.org/10.1080/1331677X.2016.1197552

Bandara, R.; Fernando, M.; \& Akter, S. 2019. Privacy concerns in E-commerce: A taxonomy and a future research agenda. Electronic Markets, 1-19. https://doi.org/10.1007/s12525-019-00375-6

Bandara, R.; Fernando, M.; \& Akter, S. 2020. Addressing privacy predicaments in the digital marketplace: A power-relations perspective. International Journal of Consumer Studies, first online. https://doi.org/10.1111/ijcs.12576 


\section{ENTREPRENEURSHIP AND SUSTAINABILITY ISSUES}

ISSN 2345-0282 (online) http://jssidoi.org/jesi/

2021 Volume 8 Number 4 (June)

https://doi.org/10.9770/jesi.2021.8.4(3)

Bansal, G.; Zahedi, F.M.; \& Gefen, D. 2016. Do context and personality matter? Trust and privacy concerns in disclosing private information online. Information \& Management 53: 1-21.

Chehabeddine, M.; Tvaronavičienè, M. 2020. Securing regional development. Insights into Regional Development 2(1): 430-442. http://doi.org/10.9770/IRD.2020.2.1(3)

Chong, A. Y.-L. 2013. Mobile commerce usage activities: The roles of demographic and motivation variables. Technological Forecasting \& Social Change 80: 1350-1359.

Cliquet, G.; Picot-Coupey, K.; Huré, E.; \& Gahinet, M.-C. 2014. Shopping with a smartphone: a French-Japanese perspective. Marketing ZFP 36 (2): 96-106.

CIGI (2028). The 2018 CIGI-Ipsos Global Survey. Retrieved from https://www.cigionline.org/internet-survey-2018

Davis, F. D. (1989). Perceived usefulness, perceived ease of use, and user acceptance of information technology. MIS Quarterly 13(3): 319-340.

Dwivedi, Y. K.; Rana, N. P.; Jeyaraj, A.; Clement, M.; \& Williams, M. D. 2019. Re-examining the unified theory of acceptance and use of technology (UTAUT): Towards a revised theoretical model. Information Systems Frontiers 21(3): 719-734. https://doi.org/10.1007/s10796-017-9774-y.

EDPR 2017. Europe`s Digital Progress Report. Retrieved from https://ec.europa.eu/digital-single-market/en/news/europes-digital-progressreport-2017

EuroCommerce 2017. Retrieved from https://www.haendlerbund.de/de/downloads/ecommerce-europe/european-ecommerce-report2018.pdf

EuroCommerce 2019. European Ecommerce Report. Retrieved from https://www.ecommerce-europe.eu/wpcontent/uploads/2019/07/European_Ecommerce_report_2019_freeFinal-version.pdf.

Groß, M. 2016. Impediments to mobile shopping continued usage intention: A trust-risk-relationship. Journal of Retailing and Consumer Services 33: 109-119.

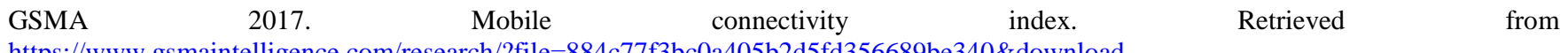
https://www.gsmaintelligence.com/research/?file=884c77f3bc0a405b2d5fd356689be340\&download

Gupta, B.; Iyer, L.S.; \& Weisskirch; R. S. 2010. Facilitating Global E-Commerce: A Comparison of Consumers'willingness to Disclose Personal Information Online in the US and in India. Journal of Electronic Commerce Research 11(1): 41-52.

Gupta, A.; \& Arora, N. 2017. Understanding determinants and barriers of mobile shopping adoption using behavioral reasoning theory, Journal of Retailing and Consumer Services 36: 1-7.

Head, M.M.; \& Hassanein, K. 2002. Trust in e-Commerce. Evaluating the Impact of Third-Party Seals, Quarterly Journal of Electronic Commerce 3(3): 307-325.

Hew, J.-J. 2017. Hall of fame for mobile commerce and its applications: A bibliometric evaluation of a decade and a half (2000-2015). Telematics and Informatics 34: 43-66.

Hillman, S.; \& Neustaedter, C. 2017. Trust and mobile commerce in North America, Computers in Human Behavior 70: 10-21.

Javaria, K.; Masood, O.; \& Garcia, F. 2020. Strategies to manage the risks faced by consumers in developing e-commerce. Insights into Regional Development, 2(4): 774-783. http://doi.org/10.9770/IRD.2020.2.4(4)

Khare, A.; \& Rakesh, S. 2012. Mobile marketing in Indian retail: a preliminary investigation of relationship and promotional endeavours through short message service, International Journal of Business Competition and Growth 2 (2): 110-128.

Ko, E.; Kim, E.Y.; \& Lee, E.K. 2009. Modeling consumer adoption of mobile shopping for fashion products in Korea, Psychology and Marketing 26 (7): 669-687. http://dx.doi.org/10.1002/mar.20294

Nielsen 2016. Mobile money. From shopping to banking to payments, how mobile is transforming commerce around the world. Retrieved from http://www.nielsen.com/content/dam/nielsenglobal/kr/docs/global-report/2016/nielsen_global_mobile_money_report_final.pdf

Lee, J.-M.; \& Rha, J.-Y. (2016). Personalization, privacy paradox and consumer conflict with the use of location-based mobile commerce. Computers in Human Behavior, 63, 453-462.

Marriott, H.R.; Williams, M.D.; \& Dwivedi, Y.K. 2017. Risk, privacy and security concerns in digital retail. The Marketing Review 17(3): 337-365. https://doi.org/10.1362/146934717X14909733966254

Mauss, M. 1925/1990. The gift: the form and reason for exchange in archaic societies. London: W.D. Halls. 


\section{ENTREPRENEURSHIP AND SUSTAINABILITY ISSUES}

ISSN 2345-0282 (online) http://jssidoi.org/jesi/

2021 Volume 8 Number 4 (June)

https://doi.org/10.9770/jesi.2021.8.4(3)

Mondego, D.; \& Gide, E. 2018. The Effect of Trust on Mobile Payment Adoption: A Comprehensive Review of Literature. International Journal of Arts \& Sciences 11(1), 375-389.

ITU. 2017. Measuring the Information Society Report 2017 - Volume 1 , Retrieved from https://www.itu.int/en/ITUD/Statistics/Documents/publications/misr2017/MISR2017_Volume1.pdf

Natarajan, T.; Balasubramanian, S.A.; \& Kasilingam, D.L. 2017. Understanding the intention to use mobile shopping applications and its influence on price sensitivity, Journal of Retailing and Consumer Services 37: 8-22.

OSI (2018). New Media Literacy Index. Open Society Institute - Sofia. Retrieved from http://osi.bg/downloads/File/2018/MediaLiteracyIndex2018 publishENG.pdf

Pachkovskyy, Y.; \& Maksymenko, A. 2016. The Young Consumer in the Ukrainian E-commerce Market. Handel Wewnętrzny 4(363): 202-216.

Rogers, E.M. (1995). Diffusion of Innovations. 4th ed., New York: The Free Press

Roghanizad, M.M.: \& Neufeld, D.J. 2015. Intuition, risk, and the formation of online trust. Computers in Human Behavior 50: $489-498$.

Venkatesh, V.; \& Bala, H. 2008. Technology Acceptance Model 3 and a research agenda on interventions. Journal of Information Technology 39/3: 273-315.

Venkatesh, V.; Thong, J.: \& Xu, X. 2012. Consumer acceptance and use of information technology: Extending the Unified Theory of Acceptance and Use of Technology. MIS Quarterly 36(1): 157-178.

Wołodźko, K.; \& Woźniak, J. 2017.The Use by Large Polish Organizations of Information about CSR Activities in e-Recruitment. Economics \& Sociology 10/2: 11-25.

Wong, C.-H.; Lee, H.S.; Lim, Y.S.; Chua, B.H.; \& Tan, G.W.-H. 2012. Predicting the consumers' intention to adopt mobile shopping: an emerging market perspective. International Journal of Network and Mobile Technologies 3(2): 24-39.

Woźniak, J. 2015. Trust and E-Commerce in the Ukraine and Poland in the Eyes of Young Urban Professionals. Review of International Comparative Management 16(2): 159-176.

Woźniak, J. 2017. Staż internetowy jako czynnik kształtujący zaufanie w m-handlu [Online experience as a factor shaping trust in mcommerce], ZeszytyNaukowe WSES w Ostrołęce 3: 263-287.

Woźniak, J.; \& Zbuchea, A. 2018. The Effect of Chosen Factors Differentiating Readiness to Provide Personal Data in M-Commerce, in Bratianu C., Zbuchea A., \& Vitelar, A. (Eds.). Strategica 2018. Challenging the Status Quo in Management and Economics. Bucharest: SNSPA, Faculty of Management/Tritonic, 730-742.

Zbuchea, A.; Vătămănescu, E.-M.; \& Pînzaru, F. 2015. M-commerce-Facts and Forecasts. A Comparative Analysis within a Triad Framework: India, Romania, and the United States. Management Dynamics in the Knowledge Economy 4(3): 387-408.

Zhang, L.; Zhung, J.; \& Liu, Q. 2012. A meta-analysis of mobile commerce adaptation and the moderating effect of culture. Computers in Human Behavior 28: 1902-1911. 


\section{ENTREPRENEURSHIP AND SUSTAINABILITY ISSUES}

ISSN 2345-0282 (online) http://jssidoi.org/jesi/

2021 Volume 8 Number 4 (June)

https://doi.org/10.9770/jesi.2021.8.4(3)

Jacek WOŹNIAK is the Professor of Human Resource Management at University of Economics and Human Sciences, Warsaw, Poland. He is currently co- editing Zarządzanie Zasoabmi Ludzkimi (Polish journal for Human Resource Management). Research interests: human resource management, management in professional and knowledge based companies, ICT in HRM.

ORCID ID: https://orcid.org/0000-0003-4610-2822

Alexandra ZBUCHEA is associate professor at National University of Political Studies and Public Administration - Faculty of Management, Bucharest, Romania. She is currently co-Editor-in-Chief of Management Dynamics in the Knowledge Economy. Research interests: m-commerce, marketing for museums and non-profit organizations, knowledge management.

ORCID ID: https://orcid.org/0000-0002-5341-7622

Make your research more visible, join the Twitter account of ENTREPRENEURSHIP AND SUSTAINABILITY ISSUES: @Entrepr69728810

Copyright (C) 2021 by author(s) and VsI Entrepreneurship and Sustainability Center

This work is licensed under the Creative Commons Attribution International License (CC BY).

http://creativecommons.org/licenses/by/4.0/

(c) (7) Open Access 